\title{
The epidemiology of bacterial vaginosis in relation to sexual behaviour
}

\author{
Hans Verstraelen ${ }^{1 *}$, Rita Verhelst ${ }^{2}$, Mario Vaneechoutte ${ }^{1}$, Marleen Temmerman ${ }^{2}$
}

\begin{abstract}
Background: Bacterial vaginosis (BV) has been most consistently linked to sexual behaviour, and the epidemiological profile of BV mirrors that of established sexually transmitted infections (STIS). It remains a matter of debate however whether BV pathogenesis does actually involve sexual transmission of pathogenic microorganisms from men to women. We therefore made a critical appraisal of the literature on BV in relation to sexual behaviour.

Discussion: G. vaginalis carriage and BV occurs rarely with children, but has been observed among adolescent, even sexually non-experienced girls, contradicting that sexual transmission is a necessary prerequisite to disease acquisition. G. vaginalis carriage is enhanced by penetrative sexual contact but also by non-penetrative digitogenital contact and oral sex, again indicating that sex per se, but not necessarily coital transmission is involved. Several observations also point at female-to-male rather than at male-to-female transmission of $G$. vaginalis, presumably explaining the high concordance rates of $G$. vaginalis carriage among couples. Male antibiotic treatment has not been found to protect against $\mathrm{BV}$, condom use is slightly protective, whereas male circumcision might protect against $\mathrm{BV}$. BV is also common among women-who-have-sex-with-women and this relates at least in part to non-coital sexual behaviours. Though male-to-female transmission cannot be ruled out, overall there is little evidence that BV acts as an STD. Rather, we suggest BV may be considered a sexually enhanced disease (SED), with frequency of intercourse being a critical factor. This may relate to two distinct pathogenetic mechanisms: (1) in case of unprotected intercourse alkalinisation of the vaginal niche enhances a shift from lactobacilli-dominated microflora to a BV-like type of microflora and (2) in case of unprotected and protected intercourse mechanical transfer of perineal enteric bacteria is enhanced by coitus. A similar mechanism of mechanical transfer may explain the consistent link between non-coital sexual acts and BV. Similar observations supporting the SED pathogenetic model have been made for vaginal candidiasis and for urinary tract infection.
\end{abstract}

Summary: Though male-to-female transmission cannot be ruled out, overall there is incomplete evidence that BV acts as an STI. We believe however that BV may be considered a sexually enhanced disease, with frequency of intercourse being a critical factor.

\section{Background}

\section{Bacterial vaginosis: a brief introduction}

Bacterial vaginosis (BV) is a condition characterised by the partial loss of the indigenous vaginal lactobacilli on the one hand, and polymicrobial anaerobic overgrowth of the vaginal mucosa on the other hand [1]. Although BV remains often asymptomatic, it still is, along with vulvovaginal candidiasis, the most common cause of vaginitis, and hence among the commonest reasons for

\footnotetext{
* Correspondence: hans.verstraelen@ugent.be

'Department of Obstetrics \& Gynaecology, Faculty of Medicine and Health Sciences, Ghent University, Ghent, Belgium
}

women to seek medical help [2]. In recent years BV has further emerged as a global issue of concern due to its association with ascending genital tract infection and with sexually transmitted infections [3]. Infections related to BV may broadly be categorized as opportunistic infections with BV-associated bacteria and as infections due to sexually transmitted agents. In the first category, ascending genital tract infection with BVrelated pathogens has been associated with postabortion [4] and postpartum endometritis [5], pelvic inflammatory disease (PID) [6,7], and, during pregnancy, late foetal loss and spontaneous preterm birth $[8,9]$. In the 
second category, BV renders women particularly vulnerable to the acquisition of Trichomonas vaginalis, Neisseria gonorrhoeae [10,11], Chlamydia trachomatis [11], HSV-2 [12] and HIV-1 [13-15]. Moreover, it has been documented that bacterial vaginosis propagates viral replication and vaginal shedding of the HIV-1 [16-18] and HSV-2 [19] viruses, thereby further enhancing the spread of these viruses.

Failure to control the high prevalence of BV has therefore now become a global issue of concern. As standard treatment with antibiotics tends to be ineffective in the long run [20], more efforts may be directed to preventive measures to reduce the incidence of BV. In particular, among the most prominent risk factors, sexual behaviour and vaginal douching are modifiable risk factors, e.g. a recent douching cessation trial documented a significant reduction in BV incidence following a douching cessation intervention [21]. Sex education may also add to the prevention of BV, provided that we have sufficient knowledge as to how sexual behaviour exactly enhances BV acquisition. Understanding the contribution of sexual activity to BV pathogenesis is therefore integral to improve the management and prevention of $\mathrm{BV}$ and to reduce its associated complications.

\section{Bacterial vaginosis and sexual behaviour}

Of all risk factors explored thus far, sexual behaviourrelated characteristics have been most consistently associated with BV. This extensive body of literature is at first sight not entirely consistent however, as BV has been associated with a variety of sexual behaviourrelated characteristics including young age at coitarche, life time number of sex partners, a recent history of multiple sex partners, and a recent history of a new sex partner. These inconsistencies make it difficult to define what genuinely represents high-risk sexual behaviour to the acquisition of BV. Possibly, different studies may have been better designed to identify certain epidemiological measures than others, while the aforementioned measures of sexual behaviour may also be interdependent. Moreover, some risk factors identified may be proxy variables to the true risk exposure, e.g. a new sex partner might be predictive to frequency of intercourse. If anything, the aforementioned risk factors all seem to point somehow at a consistent association between level of sexual activity and the odds of acquiring of BV. It remains a matter of debate however whether BV pathogenesis does actually involve sexual transmission of pathogenic micro-organisms from men to women [22].

We therefore sought to review the literature on BV epidemiology in relation to sexual behaviour thereby emphasizing on those data that could provide insight into the disease mechanisms in relation to sexual behaviour. In particular, we reviewed the data on the transmissibility of BV and the indications pro an contra transmission of BV from male to female, from female to male, from female to female, and further addressed the association between non-coital sexual behaviours in relation to $\mathrm{BV}$ and the occurrence of $\mathrm{BV}$ in sexually inexperienced women.

It may be acknowledged that the literature on BV epidemiology has largely focused on the presence of $G$. vaginalis, which is a key pathogen to BV, also numerically dominant in the biofilm mode of overgrowth in $\mathrm{BV}$, but not necessarily the BV initiating or causative agent. Throughout this review we also discuss these data on G. vaginalis, though we recognize that the patterns of sexual transmission for $\mathrm{G}$. vaginalis may not be the same as those for BV.

\section{Discussion}

\section{Observations on the transmissibility of bv}

Early experiments conducted in the 1950s and 1960s are the only studies thus far that addressed the transmissibility of BV in a direct manner. In particular, Gardner and Dukes [23] accomplished to induce BV in 11 of 15 female volunteers who were inoculated directly with vaginal secretions from patients with BV. Conversely, when they inoculated women with pure culture Gardnerella vaginalis, BV occurred in only one in 13 volunteering women. However, Criswell et al [24], did manage to induce $\mathrm{BV}$ in 7 out of 29 volunteering women when using higher inocula of pure culture Gardnerella. Hence, in these early experiments, the transmissible nature of BV had been clearly demonstrated.

The contention of $\mathrm{BV}$ as a transmissible disease then gained even more significance as epidemiological data pointed at concurrent carriage of $G$. vaginalis by women with BV and their male partners. Gardner and Dukes isolated G. vaginalis from the urethra in 45 of 47 male partners of women with BV and later on, Pheifer et al detected G. vaginalis in the urethra of 27 of 34 partners of BV patients [23,25]. Most recently, Swidsinski et al assessed $G$. vaginalis carriage in a large cross-sectional study [26] involving different population groups. Building further on the discovery of the BV biofilm $[27,28]$, Swidsinski et al first described that the presence of $G$. vaginalis can also reliably be assessed through fluorescence-in-situ-hybridisation (FISH) analysis on desquamated epithelial cells in urine in both women and men. In this study, the presence of G. vaginalis was further referred to as "dispersed" Gardnerella, consisting of loosely dispersed Gardnerella cells, and as "cohesive" Gardnerella, consisting of clustered Gardnerella cells adhesive to the epithelium, the latter indicative of the presence of the Gardnerella biofilm, previously shown an obligate finding in BV [27]. The authors enrolled among others, 20 women with symptomatic BV and 10 
of their partners and 72 consecutive married pregnant women and their 72 partners. It was shown that the 20 women with symptomatic BV consistently presented with cohesive Gardnerella as did the 10 partners investigated. Among the 72 married pregnant women and their 72 partners, dispersed Gardnerella was found in 14\% and cohesive Gardnerella in $17 \%$ of the females. Again, cohesive Gardnerella was consistently found among the partners of the women with cohesive Gardnerella, for whom the samples were analysable. No such concordance was observed for dispersed Gardnerella. Hence, the previously known strong concordance of G. vaginalis carriage by both partners when a woman has BV was herewith confirmed but further refined by the almost absolute concordance of cohesive Gardnerella carriage, which might indicate that this biofilm mode of growth represents the infectious mode of Gardnerella and/ or BV.

Following the demonstration of transmissibility of G. vaginalis isolated from pure culture, the recognition of male carriage, and the concordance of G. vaginalis carriage between couples, Piot et al provided further evidence of sexual transmission by obtaining vaginal cultures from 12 women with BV and urethral cultures from their 12 male consorts within 24 hours [29]. The G. vaginalis biotypes isolated from both partners were the same for 11 of the couples $(\mathrm{p}=0.005)$, strongly suggestive for sexual transmission of G. vaginalis.

\section{Observations that support male-to-female heterosexual transmission}

Since male G. vaginalis carriage was first demonstrated, as mentioned above, among male partners of patients with $\mathrm{BV}$, it has long been postulated that male carriage might indicate the presence of a male reservoir possibly leading to male-to-female transmission, although this assumption is not unequivocally supported by the literature. We herewith review the data on male carriage of G. vaginalis and on measures directed towards prevention of male-to-female transmission, including partner treatment with antibiotics, condom use and male circumcision.

The two largest cohort studies on male carriage of $G$. vaginalis conducted until present - both involving male attendees of a sexually transmitted disease clinic - documented male urethral carriage of G. vaginalis at a rate of $11.4 \%(49 / 430)$ in the UK [30] and of $4.5 \%(10 / 309)$ in Sweden [31]. As a matter of fact, male carriage of $G$. vaginalis may even be higher than estimated from the aforementioned studies, as urethral sampling may not be the optimal approach to document it. Kinghorn et al found a significantly higher rate of $G$. vaginalis isolation from preputial than from urethral swabs [32]. Swidsinski et al recently made a similar observation, and found that desquamated epithelial cells loaded with G. vaginalis could only reliably be recovered in a urine specimen if the praeputium was not pulled back during voiding [26]. In this manner, it was shown that among 100 men admitted to a department of internal medicine, dispersed Gardnerella occurred in $4 \%$ of males, while cohesive Gardnerella was present in 7\% [26]. In addition, several culture-based studies have also documented the presence of G. vaginalis in semen samples [33-38] - possibly pointing at a seminal or prostatic reservoir whereby in one study G. vaginalis was recovered from semen in as much as $38 \%$ of 58 men attending an infertility clinic [34]. Intriguingly, preceding the renowned description of $G$. vaginalis as the causative agent in non-specific vaginitis by Gardner and Dukes [23], the very first description of the species now known as $G$. vaginalis was in association with prostatitis [39].

Up to date, six randomized controlled trials [40-45] have addressed the effectiveness of male partner treatment in the treatment of BV. Five out of the six studies failed to document any benefit from male partner treatment with antibiotics [40-42,44,45]. It may be acknowledged here, that most of these studies suffer from multiple methodological shortcomings [46] including small sample sizes and large drop out rates. Moreover, the antibiotic regimens applied to male partners of women diagnosed with BV are mostly single doses or short courses with metronidazole or tinidazole, i.e. treatments that have been documented to be also poorly effective in women with $\mathrm{BV}$ and that are therefore not recommended by the CDC [47]. In only one of the six RCTs, a CDC-recommended regimen for women was administered to the spouses of women with BV, consisting of a 7-day course of oral clindamycin [45], though again without any noticeable effect. Finally, what one really wants to know is whether male treatment might prevent the recurrence of $\mathrm{BV}$ among their female partners, presuming that women might get re-infected from a male reservoir. This was addressed in two studies with a 3 month follow-up [42,45] whereby a recurrence rate of at least $50 \%$ among women is expected [48]. Both these studies [42,45] failed to document any benefit of male sexual partner treatment on 3 month cure rates among their female partners.

It may be concluded that the evidence suggests that there is no benefit, i.e. reduction of BV occurrence in women, by treating the sexual partners of women with BV with the drug regimens tested [46]. It may further be acknowledged that, when assuming a male-to-female route of transmission, the true effect of male treatment on the incidence of BV might at best be evaluated in a study in which male carriers would be treated prophylactically. Also, direct assessment of efficacy of antibiotic treatment for eradication of $G$. vaginalis and other 
BV-associated micro-organisms in male partners would be essential, as the lack of effect of male treatment on recurrence of $\mathrm{BV}$ in female partners not necessarily excludes male-to-female reinfection, since male treatment may not eradicate biofilm-associated G. vaginalis.

With regard to condom use as a means of preventing BV, six cross-sectional studies [49-54] yielded contradicting results. Longitudinal and cohort studies on the other hand are more in line with each other towards a beneficial effect of condom use vis-à-vis BV acquisition [55-58], although the overall observed effect tends to be rather limited with an average relative risk reduction associated with condom use estimated at merely $20 \%$ in a recent meta-analysis [59]. The two most recent studies also addressed recurrent BV [58,60]. Hutchinson et al found a very strong overall protective effect of consistent condom use on the occurrence of both incident and recurrent BV in a three-year follow-up study (adjusted odds ratio 0.37, 95\% CI 0.20-0.70) [58]. Yotebieng et al on the other hand found that consistent condom use in a 6-month follow-up study was protective against incident BV, but not against recurrent BV [60]. Hence, the evidence on consistent condom use as a protective means for $\mathrm{BV}$, overall, seems to suggest a rather moderate effect in the prevention of $\mathrm{BV}$.

If the preputial space is suspected to act as the male reservoir of BV-associated micro-organisms - as was first suggested by Kinghorn et al [32] and recently reinforced by the findings by Swidsinski et al [26], who found more $G$. vaginalis in men voiding without retracting the praeputium, then male circumcision is expected to have a protective effect on the occurrence of BV. However, results from a limited number of studies are contradictive again. In a US retrospective case-control study no difference was found in the prevalence of BV between women with circumcised partners compared to those with uncircumcised partners [61]. In a large, very well-designed, randomised controlled trial involving a large cohort of young men in Rakai, Uganda however, male circumcision was associated with a significantly decreased risk (adjusted prevalence risk ratio 0.60, 95\% CI 0.38-0.94) of BV at one year follow-up [62].

\section{Observations that support female-to-male heterosexual transmission}

One of the earliest observations casting doubt over the purportedly male-to-female sexual transmission route comes from a large cohort study on urethral carriage of G. vaginalis among men [30]. In this study, Dawson et al isolated G. vaginalis from $11.4 \%$ of urethral samples from 430 consecutive male patients attending a clinic for sexually transmitted disease [30]. Interestingly, the authors documented that the recovery rate of urethral G. vaginalis was significantly higher in heterosexual men (14.5\%) than among homosexual men (4.5\%) ( $\mathrm{p}<$ 0.001). This finding suggests that, somehow, heterosexual contact enhances male carriage of G. vaginalis, as if female-to-male transmission rather than the opposite route is at stake. Ten years later, Holst conducted an elegant experiment that corroborates this hypothesis [63]. Holst first documented that several BV-associated organisms, including Mobiluncus mulieris, M. curtisii and $G$. vaginalis, could be isolated from the urethras and/or coronal sulci of 10 in 44 male consorts (22.7\%) of women with BV. However, after two weeks of consistent condom use during regular sexual intercourse, these BV index species disappeared from all men [63], suggesting that transient carriage of BV-associated micro-organisms by men actually may ensue from (continued) female-to-male contamination during intercourse. A very recent study by Schwebke et al [64] corroborates this. In this study, Schwebke et al [64] investigated male carriage of $G$. vaginalis through species-specific PCR in urine, on a urethral swab, and on a swab obtained from the coronal sulcus from 47 men, of whom 23 were partners of women with BV and 24 were partners of women without BV. Overall, G. vaginalis was detected in 12 males. The authors observed that the 11 participants who did use a condom at the last sexual encounter were all negative for $G$. vaginalis, whereas one in three men $(12 / 36)$ who did not use a condom at the last sexual encounter was positive for Gardnerella. Moreover, none of the 5 participants who stated that they always used a condom for the past 3 months had G. vaginalis, whereas $12 / 42$ of those who did not always use a condom in the past 3 months were positive for $G$. vaginalis [64]. Thus, Schwebke et al found that G. vaginalis carriage by men is closely linked to condom use, and hence this is suggestive for a female-to-male transmission-like route of infection, as had been suggested by Holst [63] two decades ago.

These findings may at least in part explain the high concordance rates between women with BV and their male consorts as mentioned above and may further explain the low success rate of $\mathrm{BV}$ eradication in women by condom use by their partners [59].

In addition, a female-to-male route of transmission may further be consistent with the observation that $G$. vaginalis is not present in prepubertal boys, as apparent from one study involving 99 boys with negative cultures for $G$. vaginalis from the urethra, glans, and rectum [65]. In accordance, in a study comprising 50 adolescent males who had not engaged yet in sexual activity/who were sexually inexperienced, G. vaginalis was isolated from the urethra in only one [66] and in a study by the same authors, involving 50 recently married, young men in monogamous relationships with no history of STDs, G. vaginalis was isolated from none of them [66]. 


\section{Observations on bacterial vagiginosis resulting from non-coital sexual acts in heterosexuals}

Among heterosexual women, non-coital sexual behaviours, including receptive oral sex, receptive anal sex, and non-penetrative digito-genital contact have also been identified to confer an increased risk of BV acquisition.

Nandwani et al and Tchamouroff and Panja reported on a prospective cohort study, including 256 heterosexual female patients, attending a genito-urinary medicine clinic, and found a highly significant difference in the rate of $\mathrm{BV}$ among women who reported receptive oral sex in the previous four weeks (41/111 or $37 \%$ ) as compared to women who did not experience cunnilingus in the past four weeks $(14 / 145$ or $10 \%, \mathrm{p}<0.001)[67,68]$. Schwebke et al also found that an unstable microflora - as defined by the number of episodes of vaginal microflora shifting away from a Lactobacillus-dominated microbiota to a bacterial vaginosis-like profile - was significantly associated with more frequent episodes of receptive oral sex [69]. Interestingly, a similar observation has been repeatedly made with regard to cunnilingus and vaginal Candida infection $[70,71,54]$ and this was not explained by differences in extragenital carriage of Candida by the women nor by differences in extragenital and genital carriage of Candida by their partners [70].

Unprotected receptive anal sex [72,73] and unprotected receptive anal sex before vaginal intercourse [74] have also been associated with BV.

In a study involving 44 self-reported virginal women, of which 27 provided detailed information regarding sexual practices by a self-administered questionnaire, self-collected tampons were tested for G. vaginalis and A. vaginae through species-specific PCRs [75]. Surprisingly, it was found that $G$. vaginalis carriage in these virginal women was very strongly associated with oral sex and non-penetrative digito-genital contact [75]. Similarly, Fethers et al very recently documented an association among 17-21-year-old females between noncoital sexual practices (oral sex and non-penetrative digitogenital contact) and the occurrence of BV [76].

Similarly, recurrent vaginal candidiasis has also been associated with a history of recent masturbating with saliva by both the patient as her partner, while this was not explained by oral Candida carriage [70]. Recurrent urinary tract infection has also been associated with frequent masturbation [77].

\section{Observations on the occurrence of bacterial vaginosis in sexually inexperienced women}

Clearly, there is ample evidence that BV is not confined to women who are or were ever engaged in a heterosexual relationship, much in contrast to traditional STDs, indicating that heterosexual penetrative contact is definitely not a necessary prerequisite to the acquisition of BV.

Swidsinski et al investigated G. vaginalis carriage in 50 premenarchal girls and found that, dispersed Gardnerella occurred in 10\%, whereas none of the 50 girls showed cohesive, i.e. biofilm-associated, Gardnerella [26]. It has to be acknowledged here, that higher prevalence rates of G. vaginalis have been found in sexually abused girls as compared to non-abused girls in most [78-80] though not all studies [81]. Apart from G. vaginalis carriage, bacterial vaginosis in children is however rare. Anecdotically, Papanikolaou et al reported one case of recurrent BV in a 17-year old adolescent with an intact hymen [82].

In contrast, once beyond the menarche, BV also occurs among sexually inexperienced adolescents and virginal women according to several studies [83-85], albeit at lower rates on average as compared to sexually active reproductive aged-women. This contention was recently challenged however by an Australian study comprising 528 young women of which 25 women had BV [76] The largest sample up to date involved US women, entering the military, with a mean age of 19.1 years. In this study, BV in women reporting to never have had vaginal intercourse occurred at a rate of $18 \%$, whereas their sexually experienced counterparts had BV at a rate of $28 \%$ [84]. The findings on BV prevalence in the large cohort of US women entering the military are in line with those on $G$. vaginalis epidemiology with a limited number of studies also documenting higher rates of G. vaginalis carriage among sexually active adolescents. Shafer et al reported that up to one third of non-sexually active adolescents harboured G. vaginalis, which was significantly less than in sexually active adolescents (60\%) [86]. Another culture-based study of 120 asymptomatic 14- to 17-year-old females found a twofold lower prevalence of $G$. vaginalis (17\%) in women who reported no penetrative sexual activity compared with sexually active females (34\%), albeit a non-statistically significant difference [87]. So, overall, several lines of evidence corroborate that the $\mathrm{BV}$ incidence is increased by sexual activity, but clearly also contradict exclusive heterosexual transmission.

\section{Observations that support female-to-female transmission} Women with lesbian orientation or generally womenwho-have-sex-with-women (WSW) not only present rather consistently with very high rates of $\mathrm{BV}$, but monogamous lesbian couples also present with almost absolute concordance rates of vaginal microflora characteristics in terms of presence of lactobacilli in general and of hydrogen peroxide-producing lactobacilli in 
particular, in terms of presence of BV -associated organisms [88]. These observations strongly suggest femaleto-female between-partner transmission of BV. These observations may indicate strong between partner transmission or may just as well point to the higher occurrence among lesbian women of certain BV-enhancing sexual practices (see below). Indeed, lesbian women have been shown to be generally monogamous, to have low promiscuity and to have an overall low incidence of STDs [89]. Although many lesbian women do have a history of heterosexual contact, this has not been an explanatory factor to the occurrence of BV [89]. Among the common exposures investigated thus far, the very strong association between same gender sex and BV is apparently not explained by confounders such as douching, though to some extent by higher rates of smoking [89-91]. As to sexual behaviour-related characteristics among WSW, an increased frequency of sexual activity does not seem to be associated with the prevalence of BV whereas several studies found an association with increasing numbers of lifetime sexual female partners [89-91], similar to what is observed with heterosexual women. From a very detailed analysis including a number of self-reported sexual acts however, Marrazzo et al retained significant associations between BV risk among lesbians with a lack to always clean an insertive sex toy before use, with oral-anal sex, and with recent genitalgenital contact with a female partner [88]. Albeit based on a small series of patients, Tchamouroff and Panja also suggested a link between receptive oral sex and BV among WSW [68].

\section{Comment}

We reviewed the literature on BV epidemiology and extracted published data on BV in relation to sexual behaviour and thereby covered published studies and congress proceedings going back for more than half a century. We did not accomplish to unravel BV epidemiology, or to present a definite understanding of disease acquisition. A potential pitfall to our review, is that a considerable number of data reviewed relate to a single pathogen, in particular G. vaginalis, involved in a polymicrobial overgrowth condition. Though G. vaginalis is a key pathogen to $\mathrm{BV}$, also numerically dominant in the biofilm mode of overgrowth in BV, it is not necessarily the BV initiating or causative agent.

Nonetheless, several conclusions, even if partially supported by circumstantial evidence, can be put forward.

First of all, it is clear that BV differs from established STDs in as much that BV is not confined to women who are, or were, ever engaged in a heterosexual relationship, indicating that, if anything, heterosexual penetrative contact is definitely not a necessary prerequisite to the acquisition of BV.
Among children and prepubertal girls, BV is rather rare, except in case of sexual abuse, even though vaginal carriage of G. vaginalis identified through FISH is not uncommon in young girls according to one recent study [26]. Similarly, based on culture-dependent study, G. vaginalis seems to be virtually absent in prepubertal boys.

Once beyond the menarche however, BV is observed even among adolescent girls and sexually inexperienced girls, and young women in general, at an appreciable frequency, though on average at significantly lower rates as compared to sexually active adolescents and young women These findings do actually correlate well on what has been observed on the epidemiology of G. vaginalis carriage among sexually active versus non-sexually active adolescents $[86,87]$.

Girls and young women who have never engaged in penetrative sexual contact are likely to have practised non-penetrative heterosexual behaviours however, and Tabrizi et al documented that among virginal women $G$. vaginalis carriage was very strongly associated with oral sex and non-penetrative digito-genital contact [75]. Similarly, Fethers et al very recently documented an association among 17-21-year-old females between noncoital sexual practices (oral sex and non-penetrative digito-genital contact) and the occurrence of BV [76].

These studies are further in line with several other studies that have identified oral receptive sex as a risk factor for BV [67-69]. An obvious critique would be that these studies suffer from confounding, however Schwebke et al for instance performed a thorough multivariable analysis, thereby controlling for a number of factors, and found that only receptive oral sex retained significance as a risk factor to unstable vaginal microflora, indicating microflora shifting away from Lactobacillus dominance to a BV-like profile [69].

So overall, epidemiological data obtained from adolescent girls and young women, point at an alternative pathogenesis model, not observed with traditionally defined STDs, this is, while the evidence corroborates on the one hand the sexual nature of $\mathrm{BV}$, it clearly also contradicts at least to some extent a traditional infectious disease-like route of disease acquisition.

Furthermore, there is convincing evidence ensuing from condom studies [63,64], from studies among heterosexual versus homosexual men [30], and from studies among young, monogamous men $[65,66]$, that transmission of BV-associated micro-organisms may occur, however that female-to-male transmission may be a far more common route than male-to-female transmission. This sheds a completely different light on the high concordance rates of G. vaginalis carriage among couples of whom the female partner has BV, which has been a longstanding argument in favour of BV as an STD. 
Data on BV epidemiology among WSW in turn support both aforementioned pathogenetic pathways, i.e. the high rates of BV among WSW may point either at female-to-female route of transmission, either at sexual enhancement of BV occurrence through non-coital sexual behaviours, similar to what is observed among heterosexual couples. Indeed, it has been observed that WSW not only present rather consistently with very high prevalence rates of G. vaginalis and bacterial vaginosis, but also that monogamous lesbian couples present with high concordance rates of vaginal microflora characteristics in general. This was recently confirmed by Marrazzo et al in terms of concordance between Lactobacillus species shared by monogamous lesbian couples [92]. It remains elusive how this concordance is established, though likely to be sexually related. Marrazzo et al thereby also pointed at a putative disease mechanism. In particular, recent receptive digital-vaginal sex apparently affected the vaginal Lactobacillus community composition and specifically, receptive digital-vaginal sex was associated with the presence of L. gasseri, whereas the presence of L. gasseri in turn was associated with an increased BV risk [92]. The presence of L. gasseri (and L. iners) was recently also found among heterosexual pregnant women to confer an increased BV risk [93].

So as a first set of conclusions, it appears as if (1) women with BV may transmit BV-associated microorganisms to their male or female sexual partners and (2) that non-coital sexual behaviours may enhance the occurrence of $\mathrm{BV}$, which may relate to an effect of such non-penetrative heterosexual and homosexual behaviours on the Lactobacillus composition of the vaginal niche, or by the introduction of G. vaginalis and/or other BV-related anaerobes in the vagina, or by both.

Finally, while there is ample evidence that both protected and unprotected penetrative sexual behaviour is at the very least a risk marker if not a causal factor to $\mathrm{BV}$, it remains to be answered for how sexual contact is related to $\mathrm{BV}$ occurrence and whether this involves sexual transmission of BV-related micro-organisms from a male to a female host. Two alternative explanations emerge from the literature however.

Firstly, an interesting observation was published in 1971 by Leppäluoto [94]. Leppäluoto concluded - based on the study of a large series of Papanicolaou smears taken before and after unprotected coitus - that, lactobacilli-dominated precoital smears were replaced by $G$. vaginalis dominant microflora in postcoital smears [94]. Hence, coitus seems to be associated with a temporary disbalance in the delicate vaginal microflora equilibrium in favour of BV-related micro-organisms. Leppäluoto further launched the idea that the temporary imbalance of the vaginal microflora towards a BV-like profile serves sperm survival and transport, and further speculated that this imbalance is actually physiological in nature, if the microflora is allowed enough time to recover following a coital act [94]. This in turn might concur with the observation made by Vallor et al, that loss of hydrogen peroxide producing lactobacilli is primarily explained by the frequency of intercourse [95], while a lack or loss of hydrogen peroxide producing lactobacilli is a strong risk factor to the occurrence of $\mathrm{BV}$ [55,96-99].

The most straightforward explanation to this coital effect on the vaginal microflora is that unprotected sexual intercourse alters the physico-chemical vaginal environment thereby also affecting the vaginal microflora. In particular, it has been shown that the alkaline prostatic content of the ejaculate raises the vaginal $\mathrm{pH}$, which remains elevated up to eight hours following coitus [100]. The alkaline ejaculate neutralizes the vaginal $\mathrm{pH}$ and the reacidificiation rate of the vagina is estimated (based on in vitro experiments) to proceed at about $0.75 \mathrm{pH}$ units per hour in the presence of $\log 8$ lactobacilli [101]. Anaerobes grow preferably at a higher $\mathrm{pH}$. The optimum $\mathrm{pH}$ for G. vaginalis is 6 to 6.5 [102] and it is 5 for P. bivia [103]. Hence, unprotected coitus most likely induces an imbalance at the level of the vaginal growth conditions and epithelial binding sites in favour of BV-associated micro-organisms as consistently shown in a large series of postcoital smears by Leppäluoto [94]. Hence, increased coital activity may be one of the reasons why lactobacilli are losing the plot [104].

However, if this were the only mechanism involved than condom use would be expected to act as a very effective means of prevention - which it is not - and hence the proposed mechanism involving a $\mathrm{pH}$-increase does not quite explain why BV acquisition is almost equally enhanced by protected intercourse, as outlined above. Possibly, condom use might be protective against incident $\mathrm{BV}$, but this effect may be obscured in epidemiological studies due to recurrent BV in a substantial number of women, not prevented by condom use.

As a second alternative mechanism, apart from the coital pH-mediated effect on the vaginal microflora, another conceivable mechanism that may be considered is that vaginal penetration somehow promotes the transfer of perianal, perineal, and perivulvar bacteria to the vagina, thereby possibly inducing BV in some women. A similar mechanism has been observed for urinary tract infections in women, and in particular, a significantly elevated risk for urinary tract infection with E. coli associated with condom use has been observed [105], presumably involving a rectal-vestibular-urethral pathway. A most important piece of evidence to this postulate with regard to BV, comes from a study by Eschenbach et $a l$ in which they aimed to document the effects of a single episode of intercourse on the vaginal microflora 
in subjects randomly assigned to groups that used no condom or lubricated (nonspermicide) condoms [106]. It was found that the 22 subjects who used no condoms had significantly more $E$. coli at a high concentration $\left(>10^{5} \mathrm{cfu} / \mathrm{mL}\right.$ ) in the vagina following unprotected intercourse. However, among the 20 subjects who did use condoms there was also a marginally significant trend towards more vaginal E. coli $(\mathrm{p}=0.06)$ and a highly significant increase in other enteric gram-negative rods $(\mathrm{p}=0.001)$ after protected intercourse [106]. It is therefore conceivable that also other, non-coital sexual acts such as oral sex endanger the vaginal microflora through the transfer of BV-associated bacteria from the rectal and perineal regions to the vulvar region and the vagina in analogy to what has been observed for urinary tract infections [107].

Taken together, the abovementioned data suggest that unprotected intercourse may affect the vaginal microflora status through a suppressive effect on lactobacillary colonisation, on the colonisation resistance of the $\mathrm{H}_{2} \mathrm{O}_{2}$ producing lactobacilli, and through the introduction of enteric gram-negative bacteria, but equally, that even protected intercourse is associated with a significant increase of enteric bacteria in the vagina. These mechanisms therefore suggest that BV may behave as a sexually enhanced disease rather than an (exclusively) sexually transmitted infection. A critical factor - as outlined above - thereby presumably is the frequency of intercourse as has been shown for BV [95] and for urinary tract infection $[108,109]$, possibly by not granting the vaginal ecosystem to restore after a coital act.

Finally, it may be concluded that at present, there is little evidence in support of some kind of male-tofemale sexual transmission of BV-associated pathogens. It may be acknowledged however that this transmission route cannot be ruled out based on the available evidence. First, with the surge of molecular studies of the vaginal microflora, a whole new series of previously unknown bacteria has been identified with bacterial vaginosis [110,111] and it is not known whether these species might be transferred through sexual contact and whether these may act as BV-inducing micro-organisms. Secondly, there are some epidemiological data that cannot be explained solely by the sexually enhanced disease model, in particular the observation in the Rakai study [62] that male circumcision is strongly protective against $\mathrm{BV}$ acquisition, possibly pointing at the presence of BVassociated bacteria on the prepuce, as recently corroborated by Swidsinski et al [26].

In summary, while there is inconclusive evidence in support of male-to-female sexual transmission, we propose that the strong association between sexual behaviour - and level of sexual activity in particular - may be explained by an alternative pathogenetic model, which implies that BV might behave as a sexually enhanced disease rather than a sexually transmitted infection. This model is in principle consistent with most epidemiological observations cited in this review.

\section{Summary}

- G. vaginalis carriage and BV occurs rarely with children, but is common among adolescent, even sexually non-experienced girls, contradicting that sexual transmission a is necessary prerequisite to disease acquisition.

- G. vaginalis carriage is enhanced by penetrative sexual contact but also by non-penetrative digitogenital contact and oral sex, again indicating that sex per se, but not necessarily coital transmission is involved.

- Several observations also point at female-to-male rather than at male-to-female transmission of $G$. vaginalis, presumably explaining high concordance rates of G. vaginalis carriage among couples. Male antibiotic treatment has not been found to protect against BV, condom use is slightly protective, whereas male circumcision might protect against BV. - BV is also common among women-who-have-sexwith-women and this relates at least in part to noncoital sexual behaviours.

- Though male-to-female transmission cannot be ruled out, overall there is little evidence that BV acts as an STD. Rather, BV may be considered a sexually enhanced disease, with frequency of intercourse being a critical factor.

\section{Author details}

${ }^{1}$ Department of Obstetrics \& Gynaecology, Faculty of Medicine and Health Sciences, Ghent University, Ghent, Belgium. ' ${ }^{2}$ aboratory Bacteriology Research, Department of Clinical Chemistry, Microbiology, and Immunology, Faculty of Medicine and Health Sciences, Ghent University, Ghent, Belgium.

\section{Authors' contributions}

HV drafted the manuscript, MV made substantial revisions of the draft, RV and MT provided important intellectual content that added to the manuscript.

All authors read and approved the final version of the manuscript.

\section{Competing interests}

The authors declare that they have no competing interests.

Received: 25 November 2009 Accepted: 30 March 2010 Published: 30 March 2010

\section{References}

1. Sobel JD: Bacterial vaginosis. Annu Rev Med 2000, 51:349-56.

2. Nyirjesy P: Vulvovaginal candidiasis and bacterial vaginosis. Infect Dis Clin North Am 2008, 22:637-52.

3. Koumans EH, Kendrick JS, CDC Bacterial vaginosis Working Group: Preventing adverse sequelae of bacterial vaginosis: a public health program and research agenda. Sex Transm Dis 2001, 28:292-7.

4. Penney GC: Preventing infective sequelae of abortion. Hum Reprod 1997, $12: 107-12$ 
5. Jacobsson B, Pernevi P, Chidekel L, Jörgen Platz-Christensen J: Bacterial vaginosis in early pregnancy may predispose for preterm birth and postpartum endometritis. Acta Obstet Gynecol Scand 2002, 81:1006-10.

6. Haggerty CL, Hillier SL, Bass DC, Ness RB, PID Evaluation and Clinical Health study investigators: Bacterial vaginosis and anaerobic bacteria are associated with endometritis. Clin Infect Dis 2004, 39:990-5.

7. Ness RB, Kip KE, Hillier SL, Soper DE, Stamm CA, Sweet RL, Rice P, Richter HE: A cluster analysis of bacterial vaginosis-associated microflora and pelvic inflammatory disease. Am J Epidemiol 2005, 162:585-90.

8. Oakeshott P, Hay P, Hay S, Steinke F, Rink E, Kerry S: Association between bacterial vaginosis or chlamydial infection and miscarriage before 16 weeks' gestation: prospective community based cohort study. BMJ 2002, 325:1334.

9. Leitich $\mathrm{H}$, Kiss $\mathrm{H}$ : Asymptomatic bacterial vaginosis and intermediate flora as risk factors for adverse pregnancy outcome. Best Pract Res Clin Obstet Gynaecol 2007, 21:375-90.

10. Martin HL, Richardson BA, Nyange PM, Lavreys L, Hillier SL, Chohan B, Mandaliya K, Ndinya-Achola JO, Bwayo J, Kreiss J: Vaginal lactobacilli, microbial flora, and risk of human immunodeficiency virus type 1 and sexually transmitted disease acquisition. J Infect Dis 1999, 180:1863-8.

11. Wiesenfeld HC, Hillier SL, Krohn MA, Landers DV, Sweet RL: Bacterial vaginosis is a strong predictor of Neisseria gonorrhoeae and Chlamydia trachomatis infection. Clin Infect Dis 2003, 36:663-8.

12. Cherpes TL, Meyn LA, Krohn MA, Lurie JG, Hillier SL: Association between acquisition of herpes simplex virus type 2 in women and bacterial vaginosis. Clin Infect Dis 2003, 37:319-25.

13. Schwebke JR: Gynecologic consequences of bacterial vaginosis. Obstet Gynecol Clin North Am 2003, 30:685-94.

14. Spear GT, St John E, Zariffard MR: Bacterial vaginosis and human immunodeficiency virus infection. AIDS Res Ther 2007, 4:25.

15. Atashili J, Poole C, Ndumbe PM, Adimora AA, Smith JS: Bacterial vaginosis and HIV acquisition: a meta-analysis of published studies. AIDS 2008, 22:1493-501.

16. Cu-Uvin S, Hogan JW, Caliendo AM, Harwell J, Mayer KH, Carpenter CC, HIV Epidemiology Research Study: Association between bacterial vaginosis and expression of human immunodeficiency virus type 1 RNA in the female genital tract. Clin Infect Dis 2001, 33:894-6.

17. Cohn JA, Hashemi FB, Camarca M, Kong F, Xu J, Beckner SK, Kovacs AA, Reichelderfer PS, Spear GT: HIV-inducing factor in cervicovaginal secretions is associated with bacterial vaginosis in HIV-1-infected women. J Acquir Immune Defic Syndr 2005, 39:340-6.

18. Sha BE, Zariffard MR, Wang QJ, Chen HY, Bremer J, Cohen MH, Spear GT: Female genital-tract HIV load correlates inversely with Lactobacillus species but positively with bacterial vaginosis and Mycoplasma hominis. J Infect Dis 2005, 191:25-32.

19. Cherpes TL, Melan MA, Kant JA, Cosentino LA, Meyn LA, Hillier SL: Genital tract shedding of herpes simplex virus type 2 in women: effects of hormonal contraception, bacterial vaginosis, and vaginal group B Streptococcus colonization. Clin Infect Dis 2005, 40:1422-8,

20. Verstraelen $H$, Verhelst $R$ : Bacterial vaginosis: an update on diagnosis and treatment. Expert Rev Anti Infect Ther 2009, 7:1109-24

21. Brotman RM, Ghanem KG, Klebanoff MA, Taha TE, Scharfstein DO, Zenilman JM: The effect of vaginal douching cessation on bacterial vaginosis: a pilot study. Am J Obstet Gynecol 2008, 198(628):e1-7.

22. Hay P, Ugwumadu A: Detecting and treating common sexually transmitted diseases. Best Pract Res Clin Obstet Gynaecol 2009, 23:647-60.

23. Gardner HL, Dukes CD: Haemophilus vaginalis vaginitis: a newly defined specific infection previously classified non-specific vaginitis. Am J Obstet Gynecol 1955, 69:962-976.

24. Criswell BS, Ladwig CL, Gardner HL, Dukes CD: Haemophilus vaginalis: vaginitis by inoculation from culture. Obstet Gynecol 1969, 33:195-9.

25. Pheifer TA, Forsyth PS, Durfee MA, Pollock HM, Holmes KK: Nonspecific vaginitis: role of Haemophilus vaginalis and treatment with metronidazole. N Engl I Med 1978, 298:1429-34.

26. Swidsinski A, Doerffel Y, Loening-Baucke V, Swidsinski S, Verstraelen $H$, Vaneechoutte M, Lemm V, Schilling J, Mendling W: Gardnerella Biofilm involves Females and Males and is sexually transmitted. Gynecol Obstet Invest

27. Swidsinski A, Mendling W, Loening-Baucke V, Ladhoff A, Swidsinski S, Hale LP, Lochs H: Adherent biofilms in bacterial vaginosis. Obstet Gynecol 2005, 106:1013-23.
28. Swidsinski A, Mendling W, Loening-Baucke V, Swidsinski S, Dörffel Y, Scholze J, Lochs H, Verstraelen H: An adherent Gardnerella vaginalis biofilm persists on the vaginal epithelium after standard therapy with oral metronidazole. Am J Obstet Gynecol 2008, 198(97):e1-6.

29. Piot P, Van Dyck E, Peeters M, Hale J, Totten PA, Holmes KK: Biotypes of Gardnerella vaginalis. J Clin Microbiol 1984, 20:677-9.

30. Dawson SG, Ison CA, Csonka G, Easmon CS: Male carriage of Gardnerella vaginalis. Br J Vener Dis 1982, 58:243-5.

31. Holst E, Mårdh PA, Thelin I: Recovery of anaerobic curved rods and Gardnerella vaginalis from the urethra of men, including male heterosexual consorts of female carriers. Scand J Urol Nephrol Suppl 1984, 86:173-7.

32. Kinghorn GR, Jones BM, Chowdhury FH, Geary I: Balanoposthitis associated with Gardnerella vaginalis infection in men. Br J Vener Dis 1982, 58:127-9.

33. Chattopadhyay B, Teli JC: Isolation of Gardnerella vaginalis from routine genito-urinary tract specimens. J Infect 1984, 8:157-62.

34. Ison CA, Easmon CS: Carriage of Gardnerella vaginalis and anaerobes in semen. Genitourin Med 1985, 61:120-2.

35. Elsner P, Hartmann AA: Gardnerella vaginalis in the male upper genital tract: a possible source of reinfection of the female partner. Sex Transm Dis 1987, 14:122-3.

36. Lam MH, Birch DF, Fairley KF: Prevalence of Gardnerella vaginalis in the urinary tract. J Clin Microbiol 1988, 26:1130-3.

37. Hillier SL, Rabe LK, Muller CH, Zarutskie P, Kuzan FB, Stenchever MA Relationship of bacteriologic characteristics to semen indices in men attending an infertility clinic. Obstet Gynecol 1990, 75:800-4.

38. Kjaergaard N, Kristensen B, Hansen ES, Farholt S, Schønheyder HC, Uldbjerg N, Madsen H: Microbiology of semen specimens from males attending a fertility clinic. APMIS 1997, 105:566-70.

39. Leopold S: Heretofore undescribed organism isolated from the genitourinary system. US Armed Forces Med J 1953, 4:263-266.

40. Swedberg J, Steiner JF, Deiss F, Steiner S, Driggers DA: Comparison of single-dose vs one-week course of metronidazole for symptomatic bacterial vaginosis. JAMA 1985, 254:1046-9.

41. Vejtorp M, Bollerup AC, Vejtorp L, Fanøe E, Nathan E, Reiter A, Andersen ME, Strømsholt B, Schrøder SS: Bacterial vaginosis: a doubleblind randomized trial of the effect of treatment of the sexual partner. Br J Obstet Gynaecol 1988, 95:920-6.

42. Moi H, Erkkola R, Jerve F, Nelleman G, Bymose B, Alaksen K, Tornqvist E: Should male consorts of women with bacterial vaginosis be treated? Genitourin Med 1989, 65:263-8.

43. Mengel MB, Berg AO, Weaver $C H$, Herman DJ, Herman SJ, Hughes VL, Koepsell TD: The effectiveness of single-dose metronidazole therapy for patients and their partners with bacterial vaginosis. J Fam Pract 1989, 28:163-71

44. Vutyavanich T, Pongsuthirak P, Vannareumol P, Ruangsri RA, Luangsook P: A randomized double-blind trial of tinidazole treatment of the sexual partners of females with bacterial vaginosis. Obstet Gynecol 1993, 82:550-4.

45. Colli $\mathrm{E}$, Landoni M, Parazzini F: Treatment of male partners and recurrence of bacterial vaginosis: a randomized trial. Genitourin Med 1997, 73:267-70.

46. Potter J: Should sexual partners of women with bacterial vaginosis receive treatment?. Br J Gen Pract 1999, 49:913-918.

47. Centers for Disease Control and Prevention, Workowski KA, Berman SM: Sexually transmitted diseases treatment guidelines, 2006. MMWR Recomm Rep 2006, 55:1-94.

48. Joesoef MR, Schmid G: Bacterial vaginosis. Clin Evid 2005, 13:1968-1978

49. Shoubnikova M, Hellberg D, Nilsson S, Mårdh PA: Contraceptive use in women with bacterial vaginosis. Contraception 1997, 55:355-8.

50. Calzolari E, Masciangelo R, Milite V, Verteramo R: Bacterial vaginosis and contraceptive methods. Int J Gynaecol Obstet 2000, 70:341-6.

51. Smart S, Singal A, Mindel A: Social and sexual risk factors for bacterial vaginosis. Sex Transm Infect 2004, 80:58-62.

52. Chiaffarino F, Parazzini F, De Besi P, Lavezzari M: Risk factors for bacterial vaginosis. Eur J Obstet Gynecol Reprod Biol 2004, 117:222-6.

53. Schwebke JR, Desmond R: Risk factors for bacterial vaginosis in women at high risk for sexually transmitted diseases. Sex Transm Dis 2005, 32:654-8.

54. Bradshaw CS, Morton AN, Garland SM, Morris MB, Moss LM, Fairley CK Higher-risk behavioral practices associated with bacterial vaginosis compared with vaginal candidiasis. Obstet Gynecol 2005, 106:105-14. 
55. Hawes S, Hillier S, Benedietti J, Stevens CE, Koutsky LA, Wolner-Hanssen P, Holmes KK: Hydrogen peroxide-producing lactobacilli and acquisition of vaginal infections. J Infect Dis 1996, 174:1058-1063.

56. Ahmed S, Lutalo T, Wawer M, Serwadda D, Sewankambo NK, Nalugoda F, Makumbi F, Wabwire-Mangen F, Kiwanuka N, Kigozi G, Kiddugavu M, Gray R: HIV incidence and sexually transmitted disease prevalence associated with condom use: a population study in Rakai, Uganda. AIDS 2001, 15:2171-2179.

57. Baeten JM, Nyange PM, Richardson BA, Lavreys L, Chohan B, Martin HL Jr, Mandaliya K, Ndinya-Achola JO, Bwayo JJ, Kreiss JK: Hormonal contraception and risk sexually transmitted disease acquisition: results from a prospective study. Am J Obstet Gynecol 2001, 185:380-385.

58. Hutchinson KB, Kip KE, Ness RB: Condom use and its association with bacterial vaginosis and bacterial vaginosis-associated vaginal microflora. Epidemiology 2007, 18:702-8.

59. Fethers KA, Fairley CK, Hocking JS, Gurrin LC, Bradshaw CS: Sexual risk factors and bacterial vaginosis: a systematic review and meta-analysis. Clin Infect Dis 2008, 47:1426-35.

60. Yotebieng M, Turner AN, Hoke TH, Van Damme K, Rasolofomanana JR, Behets F: Effect of consistent condom use on 6-month prevalence of bacterial vaginosis varies by baseline BV status. Trop Med Int Health 2009, 14:480-6.

61. Zenilman JM, Fresia A, Berger B, McCormack WM: Bacterial vaginosis is not associated with circumcision status of the current male partner. Sex Transm Infect 1999, 75:347-8.

62. Gray RH, Kigozi G, Serwadda D, Makumbi F, Nalugoda F, Watya S, Moulton L, Chen MZ, Sewankambo NK, Kiwanuka N, Sempijja V, Lutalo T, Kagayii J, Wabwire-Mangen F, Ridzon R, Bacon M, Wawer MJ: The effects of male circumcision on female partners' genital tract symptoms and vaginal infections in a randomized trial in Rakai, Uganda. Am J Obstet Gynecol 2009, 200(42):e1-7.

63. Holst E: Reservoir of four organisms associated with bacterial vaginosis suggests lack of sexual transmission. J Clin Microbiol 1990, 28:2035-9.

64. Schwebke JR, Rivers C, Lee J: Prevalence of Gardnerella vaginalis in male sexual partners of women with and without bacterial vaginosis. Sex Transm Dis 2009, 36:92-4.

65. Wahl NG, Castilla MA, Lewis-Abney K: Prevalence of Gardnerella vaginalis in prepubertal males. Arch Pediatr Adolesc Med 1998, 152:1095-9.

66. Kumar B, Dawn G, Sharma M, Malla N: Urethral flora in adolescent boys. Genitourin Med 1995, 71:328-329.

67. Nandwani R, Uthayakumar S, Panja SK, Tchamouroff SE: Association between bacterial vaginosis and cunnilingus (abstract no. 2). 11th Meeting of the International Society for Sexually Transmitted Diseases Research, New Orleans, Louisiana 1995.

68. Tchamouroff SE, Panja SK: The association between receptive cunnilingus and bacterial vaginosis. Sex Transm Infect 2000, 76:144-5.

69. Schwebke JR, Richey CM, Weiss2 HL: Correlation of behaviors with microbiological changes in vaginal flora. J Infect Dis 1999, 180:1632-6.

70. Reed BD, Zazove P, Pierson CL, Gorenflo DW, Horrocks J: Candida transmission and sexual behaviors as risks for a repeat episode of Candida vulvovaginitis. J Womens Health (LarChmt) 2003, 12:979-89.

71. Rylander $E$, Berglund AL, Krassny $C$, Petrini B: Vulvovaginal candida in a young sexually active population: prevalence and association with orogenital sex and frequent pain at intercourse. Sex Transm Infect 2004, 80:54-7.

72. Sharma AK, Ranjan R, Mehta G: Prevalence and determinants of reproductive tract infections among women. J Commun Dis 2004, 36:93-9.

73. Chase $J L$, Bachand AM, Peel $J$, Hyatt DR, Crotsenberg A, Luben EC: Identifying potential risk factors for bacterial vaginosis and intermediate vaginal flora in Wyoming women. The 134th Annual Meeting \& Exposition of the American Public Health Association, November 4-8, 2006, Boston, MA, USA.

74. Cherpes TL, Hillier SL, Meyn LA, Busch JL, Krohn MA: A delicate balance: risk factors for acquisition of bacterial vaginosis include sexual activity, absence of hydrogen peroxide-producing lactobacilli, black race, and positive herpes simplex virus type 2 serology. Sex Transm Dis 2008, 35:78-83.

75. Tabrizi SN, Fairley CK, Bradshaw CS, Garland SM: Prevalence of Gardnerella vaginalis and Atopobium vaginae in virginal women. Sex Transm Dis 2006, 33:663-5.
76. Fethers KA, Fairley CK, Morton A, Hocking JS, Hopkins C, Kennedy L, Fehler G, Bradshaw CS: Early sexual experiences and risk factors for bacterial vaginosis. J Infect Dis 2009, 200:1662-70.

77. Tchoudomirova K, Mårdh PA, Kallings I, Nilsson S, Hellberg D: History, clinical findings, sexual behavior and hygiene habits in women with and without recurrent episodes of urinary symptoms. Acta Obstet Gynecol Scand 1998, 77:654-9.

78. Bartley DL, Morgan L, Rimsza ME: Gardnerella vaginalis in prepubertal girls. Am J Dis Child 1987, 141:1014-7.

79. Gardner JJ: Comparison of the vaginal flora in sexually abused and nonabused girls. J Pediatr 1992, 120:872-7.

80. Steele AM, de San Lazaro C: Transhymenal cultures for sexually transmissible organisms. Arch Dis Child 1994, 71:423-7.

81. Ingram DL, White ST, Lyna PR, Crews KF, Schmid JE, Everett VD, Koch GG: Gardnerella vaginalis infection and sexual contact in female children. Child Abuse Negl 1992, 16:847-53.

82. Papanikolaou EG, Tsanadis G, Dalkalitsis N, Lolis D: Recurrent bacterial vaginosis in a virgin adolescent: a new method of treatment. Infection 2002, 30:403-4.

83. Bump RC, Buesching WJ: Bacterial vaginosis in virginal and sexually active adolescent females: evidence against exclusive sexual transmission. Am J Obstet Gynecol 1988, 158:935-9.

84. Yen S, Shafer MA, Moncada J, Campbell CJ, Flinn SD, Boyer CB: Bacterial vaginosis in sexually experienced and non-sexually experienced young women entering the military. Obstet Gynecol 2003, 102:927-33.

85. Vaca M, Guadalupe I, Erazo S, Tinizaray K, Chico ME, Cooper PJ, Hay P: High prevalence of bacterial vaginosis in adolescent girls in a tropical area of Ecuador. BJOG 2010, 117:225-8.

86. Shafer MA, Sweet RL, Ohm-Smith MJ, Shalwitz J, Beck A, Schachter J: Microbiology of the lower genital tract in postmenarchal adolescent girls: differences by sexual activity, contraception, and presence of nonspecific vaginitis. J Pediatr 1985, 107:974-81.

87. Bump RC, Sachs LA, Buesching WJ: Sexually transmissible infectious agents in sexually active and virginal asymptomatic adolescent girls. Pediatrics 1986, 77:488-94.

88. Marrazzo JM, Koutsky LA, Eschenbach DA, Agnew K, Stine K, Hillier SL: Characterization of vaginal flora and bacterial vaginosis in women who have sex with women. J Infect Dis 2002, 185:1307-13.

89. McCaffrey M, Varney P, Evans B, Taylor-Robinson D: Bacterial vaginosis in lesbians: evidence for lack of sexual transmission. Int J STD AIDS 1999 10:305-8.

90. Bailey JV, Farquhar C, Owen C: Bacterial vaginosis in lesbians and bisexual women. Sex Transm Dis 2004, 31:691-4

91. Evans AL, Scally AJ, Wellard SJ, Wilson JD: Prevalence of bacterial vaginosis in lesbians and heterosexual women in a community setting. Sex Transm Infect 2007, 83:470-5.

92. Marrazzo J, Thomas K, Fiedler T, Fredricks D: Risks for acquisition of bacterial vaginosis among women who have sex with women. 18th Meeting of the International Society for Sexually Transmitted Diseases Research, London, UK 2009.

93. Verstraelen $H$, Verhelst $R$, Claeys G, De Backer E, Temmerman M, Vaneechoutte M: Longitudinal analysis of the vaginal microflora in pregnancy suggests that $L$. crispatus promotes the stability of the normal vaginal microflora and that $L$. gasseri and/or $L$. iners are more conducive to the occurrence of abnormal vaginal microflora. BMC Microbiol 2009, 9:116.

94. Leppäluoto PA: Autopsy of bacterial vaginosis: a physiological entity rather than a contagious disease. Acta Obstet Gynecol Scand 2008, 87:578-9.

95. Vallor AC, Antonio MA, Hawes SE, Hillier SL: Factors associated with acquisition of, or persistent colonization by, vaginal lactobacilli: role of hydrogen peroxide production. J Infect Dis 2001, 184:1431-6.

96. Klebanoff SJ, Hillier SL, Eschenbach DA, Waltersdorph AM: Control of the microbial flora of the vagina by $\mathrm{H} 2 \mathrm{O} 2$-generating lactobacilli. J Infect Dis 1991, 164:94-100.

97. Hillier SL, Krohn MA, Klebanoff SJ, Eschenbach DA: The relationship of hydrogen peroxide-producing lactobacilli to bacterial vaginosis and genital microflora in pregnant women. Obstet Gynecol 1992, 79:369-73.

98. Hillier SL, Krohn MA, Rabe LK, Klebanoff SJ, Eschenbach DA: The normal vaginal flora, $\mathrm{H} 2 \mathrm{O} 2$-producing lactobacilli, and bacterial vaginosis in pregnant women. Clin Infect Dis 1993, 16:S273-81. 
99. Antonio MA, Rabe LK, Hillier SL: Colonization of the rectum by Lactobacillus species and decreased risk of bacterial vaginosis. J Infect Dis 2005, 192:394-8.

100. McGregor JA, French J: Bacterial vaginosis in pregnancy. Obstet Gynecol Surv 2000, 55:S1-19.

101. Boskey ER, Telsch KM, Whaley KJ, Moench TR, Cone RA: Acid production by vaginal flora in vitro is consistent with the rate and extent of vaginal acidification. Infect Immun 1999, 67:5170-5.

102. Greenwood JR, Pickett MJ: Transfer of Haemophilus vaginalis Gardner and Dukes to a new genus, Gardnerella: G. vaginalis (Gardner and Dukes) comb. nov. Int J Syst Bacteriol 1980, 30:170-178.

103. Shah HN, Collins DM: Prevotella, a new genus to include Bacteroides melaninogenicus and related species formerly classified in the genus Bacteroides. Int J Syst Bacteriol 1990, 40:205-8.

104. Hay P: Life in the littoral zone: lactobacilli losing the plot. Sex Transm Infect 2005, 81:100-2

105. Foxman B, Marsh J, Gillespie B, Rubin N, Koopman JS, Spear S: Condom use and first-time urinary tract infection. Epidemiology 1997, 8:637-41.

106. Eschenbach DA, Patton DL, Hooton TM, Meier AS, Stapleton A, Aura J, Agnew K: Effects of vaginal intercourse with and without a condom on vaginal flora and vaginal epithelium. J Infect Dis 2001, 183:913-8.

107. Foxman B, Brown P: Epidemiology of urinary tract infections: transmission and risk factors, incidence, and costs. Infect Dis Clin North Am 2003, 17:227-41.

108. Scholes D, Hooton TM, Roberts PL, Stapleton AE, Gupta K, Stamm WE: Risk factors for recurrent urinary tract infection in young women. $J$ Infect Dis 2000, 182:1177-82.

109. Nguyen $\mathrm{RH}$, Swanson $\mathrm{D}$, Harlow BL: Urogenital infections in relation to the occurrence of vulvodynia. J Reprod Med 2009, 54:385-92.

110. Verhelst R, Verstraelen $H$, Claeys $G$, Verschraegen $G$, Delanghe J, Van Simaey L, De Ganck C, Temmerman M, Vaneechoutte M: Cloning of $16 \mathrm{~S}$ rRNA genes amplified from normal and disturbed vaginal microflora suggests a strong association between Atopobium vaginae, Gardnerella vaginalis and bacterial vaginosis. BMC Microbiol 2004, 4:16

111. Fredricks DN, Fiedler TL, Marrazzo JM: Molecular identification of bacteria associated with bacterial vaginosis. N Engl J Med 2005, 353:1899-911.

\section{Pre-publication history}

The pre-publication history for this paper can be accessed here: http://www. biomedcentral.com/1471-2334/10/81/prepub

doi:10.1186/1471-2334-10-81

Cite this article as: Verstraelen et al:: The epidemiology of bacterial vaginosis in relation to sexual behaviour. BMC Infectious Diseases 2010 $10: 81$.

\section{Submit your next manuscript to BioMed Central and take full advantage of:}

- Convenient online submission

- Thorough peer review

- No space constraints or color figure charges

- Immediate publication on acceptance

- Inclusion in PubMed, CAS, Scopus and Google Scholar

- Research which is freely available for redistribution 